\title{
Use of Aqueous Extract of Pseuderanthemum acuminatissimum Radlk Leaves To Mediate The Synthesis of Gold Nanoparticles and Their Anti Eschericia coli Activity
}

\author{
S. SALPRIMA YUDHA ${ }^{1 *}$, TOTOK EKA SUHARTO ${ }^{1}$, EKA ANGASA ${ }^{1}$, \\ YUTA NISHINA ${ }^{2}$, ZULFIKRI ACHID MARDLIA ${ }^{1}$ and SIPRIYADI ${ }^{3}$
}
${ }^{1}$ Department of Chemistry, Faculty of Mathematics and Natural Sciences, The University of Bengkulu, Jalan Raya W.R Supratman, Kandang Limun 38371A, Bengkulu, Indonesia.
${ }^{2}$ Research Core for Interdisciplinary Sciences, Okayama University, Tsushima-naka, Kita-Ku Okayama, 700-8530 Japan.
${ }^{3}$ Department of Biology, Faculty of Mathematics and Natural Sciences, The University of Bengkulu, Jalan Raya W.R Supratman, Kandang Limun 38371A, Bengkulu, Indonesia.
*Corresponding author E-mail: salprima@unib.ac.id

http://dx.doi.org/10.13005/ojc/330221

(Received: January 05, 2017; Accepted: February 02, 2017)

\begin{abstract}
This research provides a new route to obtain gold nanoparticles (AuNPs) using an aqueous extract of air-dried Pseuderanthemum acuminatissimum Radlk leaves. The extract was used as a reducing agent in the formation of metallic gold from gold ions, and acted as a stabilizer of the obtained AuNPs in the reaction mixture. The formation of AuNPs in aqueous extract of $P$. acuminatissimum Radlk leaves was validated by change in color and the appearance of surface plasmone resonance (SPR) peak at $552 \mathrm{~nm}$. The average size of the gold nanoparticles was $63 \mathrm{~nm}$, and irregular shapes were observed in the reaction mixture. Fourier transform infrared spectroscopy (FT-IR) reveals the presence of organic compound containing hydroxyl functional groups in the air-dried $P$. acuminatissimum Radlk leaves, which predicted to be the most responsible for the reduction of gold ions to form metallic gold. The antibacterial properties of the gold nanoparticles were studied using Escherichia coli (ATCC 8739 TM$^{*}$ ) strain; the AuNPs significantly inhibited the growth of E. coli indicated by a slight increase in the size of the inhibition zone as the volume of added nanocolloid was increased. Therefore, the present study indicated the promising of green synthesis of AuNPs using biological agents and as a potential material to inhibit the bacterial growth.
\end{abstract}

Keywords: Gold nanoparticles; Pseuderanthemum acuminatissimum

Radlk; Escherichia coli; inhibition capacity.

\section{INTRODUCTION}

Functionalized gold nanoparticles (AuNPs) have potential as antimicrobial materials to counter, for example, fungi and bacteria ${ }^{1}$. Increasing efforts have been dedicated to research in this field, especially in the development of metal nanoparticles (such as copper, silver and gold nanoparticles) as 
antibacterial agents ${ }^{1-4}$. The most common target for antibacterial agents has been gram-negative bacteria, owing to the multi-drug resistance phenomena observed in gram-negative bacteria 2-5.

Developments in this area have been inspired by the need to find the type of metal nanoparticles, and the functionalization of such nanoparticles, that will display the greatest growth inhibition capacity toward gram-negative bacteria. Efforts toward meeting these main criteria have been reported by several researchers; for example, the synthesis of gold nanoparticles in the presence of cetyltriammonium bromide (CTAB) was reported to produce agents with antimicrobial activity toward $E$. coli (ATCC 29522 strain). In this case, the reduction of the gold ions to metallic gold was performed using citric acid ${ }^{2}$. Dextrose-encapsulated AuNPs have been prepared, and the produced nanoparticles were effective in inhibiting the growth of E.coli and S.epidermis ${ }^{3}$. Gold nanorods with various aspect ratios were investigated, and the results showed that the gold nanorods had higher inhibitory activity than spherical nanoparticles ${ }^{6}$. Aquatic plants were also reported to be useful for the biogenic synthesis of metal nanoparticles, in a report on the synthesis of gold nanoparticles using seaweed biomass; the product in question was also effective in inhibiting the growth of several species of bacteria ${ }^{7}$. In addition, the utility of bacillus sp. for the synthesis of gold nanoparticles and their performance against multidrug-resistant strains was studied using a standard bioassay ${ }^{8}$.

Some molecular mechanisms explaining the action of AuNPs toward E. coli have been proposed; for example, the antibacterial capacity was proposed to follow two mechanisms, in which the gold nanoparticles change the potential of the cell membrane and inhibit ATP synthase activity ${ }^{9}$. It has been shown that gold nanoparticles will inhibit the sub-unit of ribosome for tRNA binding To provide a mechanistic insight into the action of gold nanoparticles toward a broad spectrum of microba, investigations were performed using biogenic AuNPs and a bacterial biomass of bacillus megaterium ${ }^{10}$.

The "green" synthesis of nanomaterials is of great interest for a wide range applications; in some such techniques, surface modification is performed using modifiers and/or capping agents, to modify the physicochemical properties of the core material ${ }^{11}$. Motivated by these issues, this study aimed to provide a good alternative technique for the synthesis of gold nanoparticles using local resources, specifically an aqueous extract of air-dried P.acuminatissimum Radlk leaves. Small amounts of the resulting biosynthetic nanoparticles were introduced into media containing E. coli (ATCC 8739 $\mathrm{TM}^{\star}$ ) Strain, and the subsequent growth of the E. coli was observed.

\section{MATERIALS AND METHOD}

The $P$. acuminatissimum Radlk leaves were obtained from Enggano island in Bengkulu, Indonesia, and dried in open-air conditions. $\mathrm{HAuCl}_{4}$ was purchased from Sigma-Aldrich, and was used as received. Fourier transform infra-red spectroscopy (FT-IR) was used to determine the functional groups of the pieces of air-dried $P$. acuminatissimum Radlk leaves. The preparation of the leaf extract and the reaction steps for the AuNPs synthesis were in line with our previous reports ${ }^{12-13}$, as follows: after boiling of the air-dried $P$. acuminatissimum Radlk leaves $(0.5 \mathrm{~g})$ in $25 \mathrm{ml}$ of demineralized water under stirring for 15 minutes, the reaction mixture was separated using a Whatman 42 paper filter. A $0.01 \mathrm{M}$ solution of $\mathrm{HAuCl}_{4}(1 \mathrm{ml})$ was then added dropwise to the fresh filtrate of $P$. acuminatissimum Radlk leaves ( 5 $\mathrm{ml}$ ), under vigorous stirring at room temperature. UV-Vis spectrophotometry, transmission electron microscopy (TEM), and particle size analysis (PSA) were applied to investigate the reaction progress, and to perform product analysis. Inhibition capacity

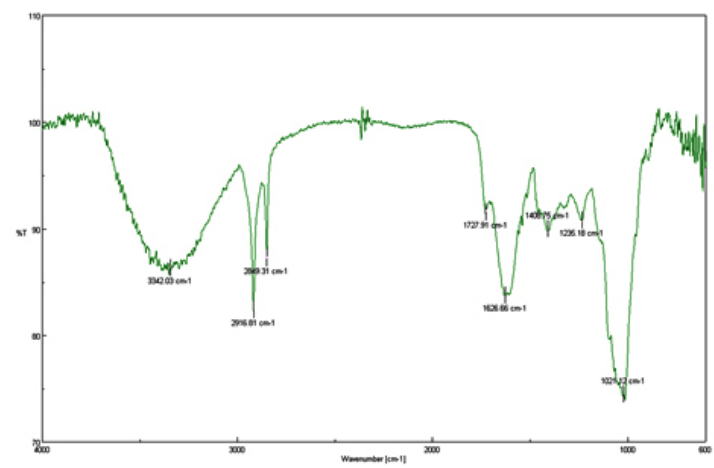

Fig. 1: FTIR patern of air-dried $P$. acuminatissimum Radlk) leaves 
studies of the reaction mixture of gold nanoparticles and leaf extract (called AuNPs@ @. acuminatissimum Radlk leaf extract) was carried out following a procedure detailed in our previous report ${ }^{14}$, as follows: nutrient agar (NA) powder was dissolved in $1000 \mathrm{ml}$ of demineralized water; the solution was then boiled and sterilized in an autoclave operated at $120^{\circ} \mathrm{C}$ for 15 minutes, to obtain NA media in a dish. The same procedure was applied for the preparation of nutrient broth (NB) using 8 grams of NB powder. Regenerated E. coli (ATCC 8739 TM$^{*}$ strain) was used to investigate the inhibition capacity of the nanoparticles, using the paper diffusion method. The paper disc diameter was $6 \mathrm{~mm}$. The inhibition zone of samples treated using various volumes of AuNPs@P. acuminatissimum Radlk (10 $\mu \mathrm{L} ; 20 \mu \mathrm{L}$; $30 \mu \mathrm{L}$ ) was measured in millimeters.

\section{RESULTS and DISCUSSIONS}

When the air-dried $P$. acuminatissimum Radlk leaves were subjected to FTIR measurements, some significant peaks were observed, as shown in Fig. 1. The important peaks were at $3342.0 \mathrm{~cm}^{-1}$ (OH stretching), $2916.8 \mathrm{~cm}^{-1}$ and $2849.3 \mathrm{~cm}^{-1}(\mathrm{C}-\mathrm{H}$ stretching), and $1727.9 \mathrm{~cm}^{-1}(\mathrm{C}=\mathrm{O}$ stretching).

It was important to determine which functional groups were present in the leaves, to predict their capacity for the reduction of metal ions to metal nanoparticles. The presence of hydroxyl functional groups indicated the possibility to form carbonyl groups as a result of the oxidation step, which would couple with the reduction step of the gold ions to form metallic gold.

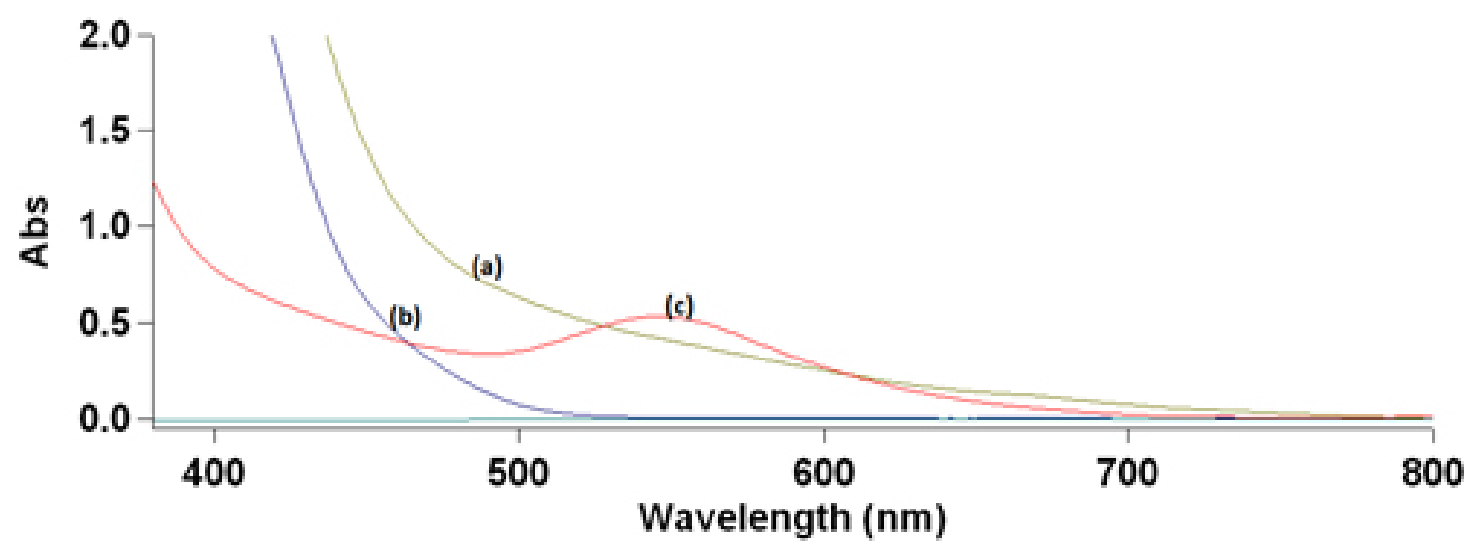

(A)

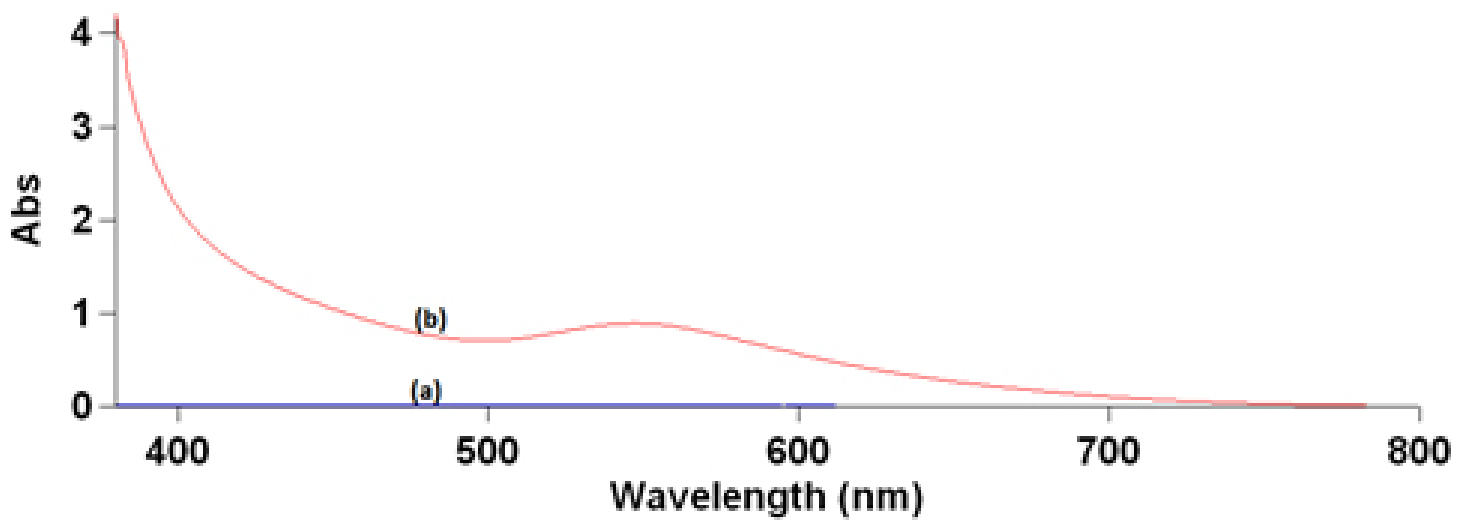

(B)

Fig. 2.: (A) UV-Vis patern of (a) $P$. acuminatissimum Radlk leaf extract, (b) $\mathrm{HAuCl}_{4} \mathbf{0 , 0 1} \mathrm{M}$;

(c) mixture of leaf extract and $\mathrm{HAuCl}_{4}$ after $\sim 45$ minutes; (B) UV-Vis patern of

(a) Spectrum of blank solution, (b) solution containing of leaf extract and $\mathrm{HAuCl}_{4}$ after 48 hours 
The synthesis of AuNPs using $P$. acuminatissimum Radlk leaf extract was performed under mild reaction conditions at room temperature, without any additional reduction agent. When the gold ion solution $\left(\mathrm{HAuCl}_{4} 0.01 \mathrm{M}\right)$ was added to the $P$. acuminatissimum Radlk leaf extract, an almostblack solution was observed immediately. This visual observation of the color change, which acted as a first indication, was supported by results from UVVis spectroscopy analysis, the results of which are shown in Fig. 2A and Fig. 2B.

Figure $2 \mathrm{~A}$ shows that the leaf extract initially did not yield any peak when the extract solution was subjected to UV-Vis spectrophotometry measurements at wavelengths from $380 \mathrm{~nm}$ to 800 $\mathrm{nm}$. The same was true of the $\mathrm{HAuCl}_{4}$ solution. Because the reaction was performed at room temperature, the nucleation started very quickly, and most of the $\mathrm{Au}(\mathrm{III})$ was converted to $\mathrm{Au}(0)$ during the first 30-45 minutes of the reaction. This was clearly reflected in the UV-Vis spectra of the solution, in which a new absorption peak at $522 \mathrm{~nm}$ appeared during the initial measurements. The appearance of a new peak at $552 \mathrm{~nm}$ provided evidence that the AuNPs were formed in the $P$. acuminatissimum Radlk leaf extract medium/reaction system. Further, after the reaction mixture was maintained at room temperature for 48 hours, and the sample was

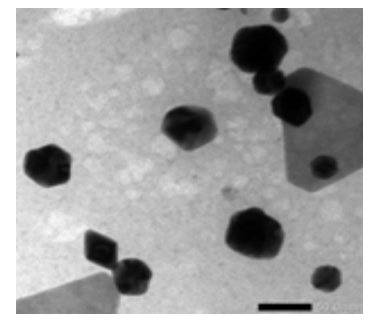

a

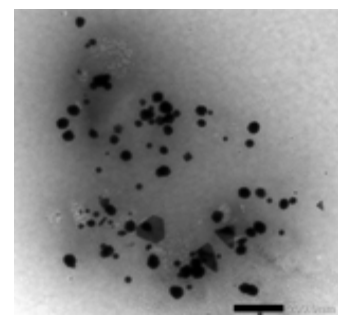

b

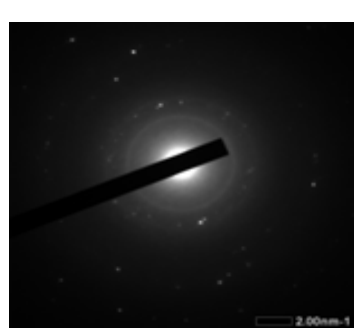

C

Fig. 3: TEM patern of AuNPs@P. acuminatissimum Radlk leaves extract reanalyzed using the same wavelength range, the mixture showed similar peaks, without the addition of any capping agent to the reaction mixture (Fig. 2B).

A surface plasmon resonance (SPR) peak was observed for the AuNPs at around 500-600 nm, as shown in Figure 2B, indicating that the compounds in the $P$. acuminatissimum Radlk leaf extract prevented aggregation of the metals (good nucleation stability); stability is important for the application of AuNPs, as, for example, catalysts or antibacterial agents. The morphology of the nanoparticles was analyzed using TEM, and the results are shown in Fig. 3.

The overview image in Fig. 3a illustrates the morphology and size distribution of the as-prepared AuNPs; the scale bar is $200 \mathrm{~nm}$. A magnified overview image (Fig. 3b) with a scale bar of $50 \mathrm{~nm}$ illustrated the presence of an organic layer around the nanoparticles (as shown by the light contrast behind the particles). The nature of the crystalline gold nanoparticles was indicated by the bright circular spots in Fig 3c. In general, the diameter of the metal nanoparticles could be determined by measuring the size of particles in the TEM images. However, the TEM results in Fig $3 a$ and $3 b$ showed that the obtained AuNPs had an irregular shape, which prevented an accurate size determination. An alternative known method of analyzing non-spherical particles uses dynamic light scattering; the particle size analysis (PSA) technique was applied here, and the results are shown in Fig. 4.

According to the size distribution curve shown in Fig. 4, the AuNPs, mostly ranged from 50 to $100 \mathrm{~nm}$ in size, and had a mean diameter of approximately $63 \mathrm{~nm}$; this was in agreement with the TEM results shown in Fig. $3 a$ and $3 b$.

To explore the possible applications of the current AuNPs, the antibacterial activity of the AuNPs synthesized using $P$. acuminatissimum Radlk leaf extract was tested in terms of the inhibition capacity toward E. Coli growth, using the paper disc method (using a paper disc with a diameter of $6 \mathrm{~mm}$ ) (Fig. 5). 


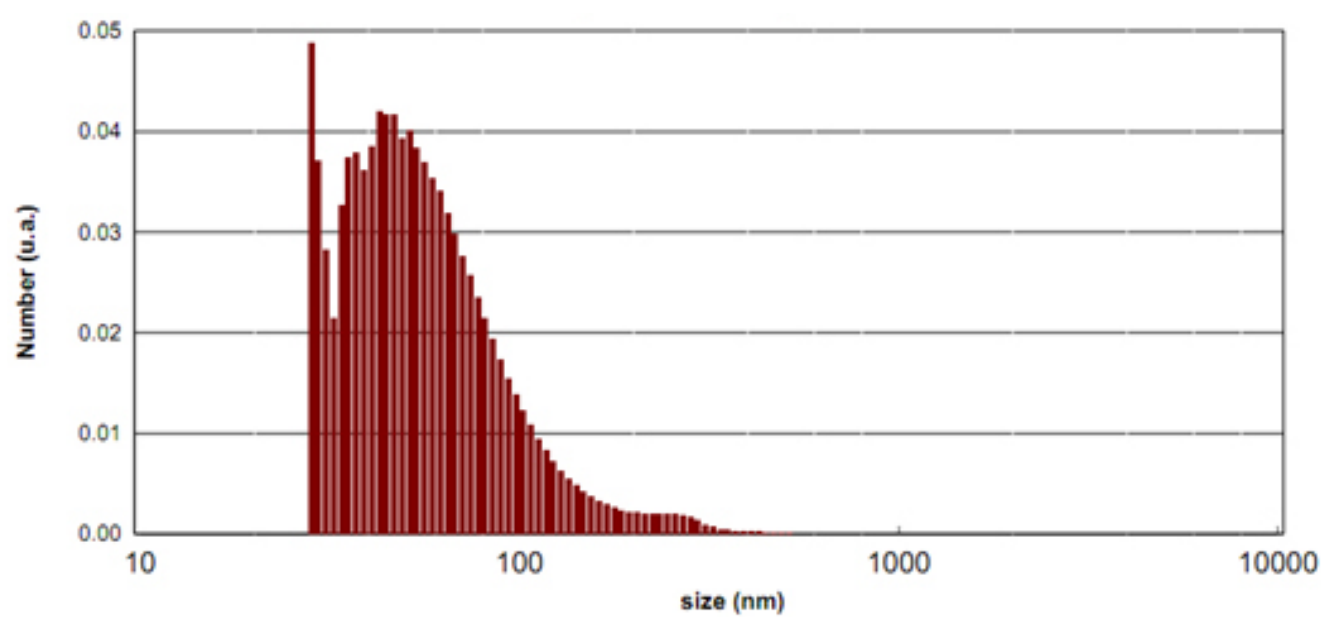

Fig. 4: Size Distribution of AuNPs@P. acuminatissimum Radlk leaves extract

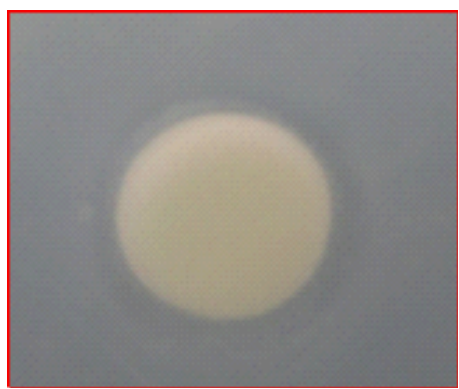

(a)

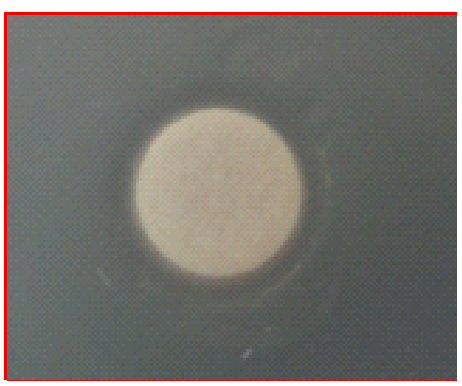

(c)

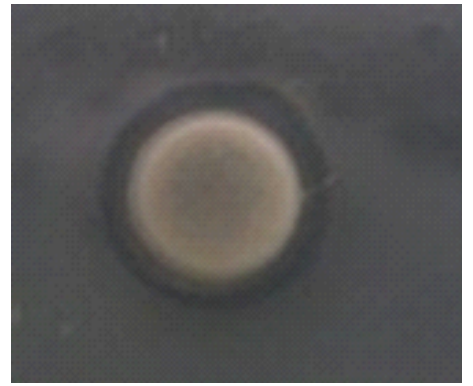

(b)

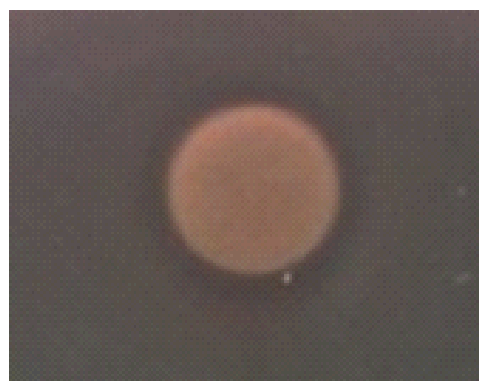

(d)

Fig. 5: Representative photograps of bacterial growth in treated medium with (a) $P$. acuminatissimum Radlk leaves extract, (b) $10 \mu \mathrm{L}$ of AuNPs@P. acuminatissimum Radlk leaves extract (c) $20 \mu \mathrm{L}$ of AuNPs@P. acuminatissimum Radlk leaves extract, (d) $30 \mu \mathrm{L}$ of AuNPs@P. acuminatissimum Radlk leaves extract

As reported in the literature ${ }^{15}$, AuNPs actively inhibit bacterial growth, for gram negative bacteria such as E. coli, and for gram positive such as staphylococcus $s p$. Figure 5 shows that the aqueous extract of $P$. acuminatissimum Radlk leaves itself had an inhibiting effect on the E. coli growth (Fig. $5 a)$, as indicated by the presence of a transparent zone around the paper disc. Moreover, the reaction mixture of AuNPs and leaf extract (AuNPs@P. acuminatissimum Radlk leaf extract) produced a larger defined transparent zone (Fig. 5b-5d). These results were clearly in line with other results claiming that the activity of AuNPs toward bacteria is a result of their small size, increased surface area, and good penetrating power ${ }^{16}$. It has been reported that the inhibition capacity is also because of changes in 
Table 1. Inhibition Zone of $E$. Coli growth in the presence of AuNPs @ P. acuminatissimum Radlk leaves extract

\begin{tabular}{|c|c|c|c|}
\hline Entry & $\begin{array}{c}\text { Amount of } \\
\text { AuNPs @ } P \text {. } \\
\text { acuminatissimum } \\
\text { Radlk } \\
\text { leaves } \\
\text { extract }(\mu \mathrm{L})\end{array}$ & $\begin{array}{c}\text { Inhibition } \\
\text { zone + } \\
\text { paper disc } \\
\text { diameter } \\
(\mathrm{mm})\end{array}$ & $\begin{array}{c}\text { Average } \\
\text { (mm) }\end{array}$ \\
\hline 1 & 10 & $\begin{array}{l}9 \\
7 \\
7\end{array}$ & 7,67 \\
\hline 2 & 20 & $\begin{array}{c}9 \\
8,5 \\
8,5\end{array}$ & 8,67 \\
\hline 3 & 30 & $\begin{array}{c}9,5 \\
9 \\
9\end{array}$ & 9,17 \\
\hline 4 & $30 \mu \mathrm{L}$ extract only & $\begin{array}{c}7 \\
7 \\
7,2\end{array}$ & 7.06 \\
\hline
\end{tabular}

protein structure, and nanoparticle features ${ }^{17}$. The measurement results for the inhibition zone (diameter in millimeters) are summarized in Table 1.

Table 1 shows that the AuNPs in the $P$. acuminatissimum leaf extract medium had an inhibiting effect on the $E$. coli growth; there was a slight increase in the size of the inhibition zone as the volume of added nanocolloid was increased (entries 1-3). The aqueous air-dried $P$. acuminatissimum Radlk leaf extract itself also had an inhibiting effect on the E. coli growth (entry 4), but the effect was decreased compared with the effect produced by the same volume of the AuNPs@P. acuminatissimum Radlk leaf extract (entry 3). As a control experiment, to determine the environmental effects of the medium growth, the paper dish was treated using demineralized water, and the final result showed that the demineralized water did not produce any inhibitory effect. It was clear that the current gold nanoparticles in the $P$. acuminatissimum Radlk leaf extract medium (AuNPs@P. acuminatissimum Radlk leaf extract) represent a potential alternative material for antibacterial action against $E$. coli. The results also support previous results demonstrating the utility of potential plant extracts for the synthesis of gold nanoparticles and for increasing their activity as antibacterial agents ${ }^{14,18}$.

\section{CONCLUSION}

The findings of this study suggested that AuNPs prepared via the mixing of a gold ion solution with $P$. acuminatissimum Radlk leaf extract were irregular in shape, based on TEM images. The PSA results showed a narrow particle size distribution with an average diameter of $63 \mathrm{~nm}$, and UV-visible absorption spectra indicated the special surface plasmon resonance (SPR) for AuNPs at $522 \mathrm{~nm}$. A bioassay using the AuNPs exhibited antibacterial activity against a selected $E$. coli strain.

\section{ACKNOWLEDGEMENTS}

Funding for this research was provided by the Ministry of Research, Technology and Higher Education (Kemenristekdikti) of Indonesia. Z.A.M. thanks the Department of Chemistry for the opportunity to work as a research assistant.

\section{REFERENCES}

1. Li, X., Robinson, S.M., Gupta, A., Saha, K., Jiang, Z., Moyano, D. F., Sahar, A., Riley, M. A., Rotello, V. M. ACS Nano. 2014, 8 (10), 10682-10686.

2. Azam, A., Ahmed, F., Arshi, N., Chaman, M., Naqvi, A.H. Intl J. Theoretical \& Applied Sci., 2014, 1(2), 1 - 4 .
3. Badwaik, V. D., Vangala, L. M., Pender, D. S , Willis, C. B., Aguilar, Z. P., Gonzalez, M. S., Paripelly, R., Dakshinamurthy, R. Nanoscale Res. Lett., 2012, 7, 623.

4. Zhou, Y., Kong, Y., Kundu, S., Cirillo, J. D., Liang, H. J. Nanobiotech, 2012, 10, 19 - 28.

5. Zhao, Y., Tian, Y., Cui, Y., Liu, W., Ma, W., 
Jiang, X., J. Am. Chem. Soc., 2010, 132, 12349-12356 9.

6. Sharma, S., Manhar, A. K., Bora, P. J., Dolui, S. K., Mandal, M. Adv. Mater. Lett., 2015, 6 (3), 235-241.

7. Rajathi, F. A. A., Parthiban, C., Kumar, V. G., Anantharaman, P., 2012, 99, 166-173.

8. Roshmi, T., Soumya, K. R., Jyothis, M., Radhakrishnanm, E. K. Gold Bull., 2015, 48, 63-71.

9. Cui, Y., Zhao, Y., Tian, Y., Zhang, W., Lü, X., Jiang, X., Biomaterials, 2012, 33, 2327 2333.

10. Jena, S., Das, B., Bosu, R., Suar, M., Mandal, D. J. Clust. Sci., published online 12 May 2015. doi: 10.1007/s10876-015-0869-7.

11. De Jong, W., Borm, P. Int. J. Nanomedicine. 2008. 311, 133-149.

12. Yudha S., S., Mardlia, Z. A., Angasa, E., Suharto T. E., Nishina, Y. Proceeding of $9^{\text {th }}$
Joint Conference on Chemistry, Semarang, Indonesia. 2014, 85-88.

13. Yudha S., S., Angasa, E., Suharto, T.E., Nishina, Y., Mardlia, Z.A. Res. J. Pharm. Bio. Chem. Sci., 2015, 6, 1802.

14. Yudha S., S., Angasa, E., Suharto, T. E., Nishina, Y., Mardlia, Z. A., Sipriyadi. AIP Conf. Proc. 1710, 030017. 2016, http://dx.doi. org/10.1063/1.4941483

15. Zhang, Y., Dasari, T. P. S., Deng, H., Yu, H., 2015. J. Env. Sci. and Health, Part C: Env. Carcinogenesis and Ecotoxicology Rev., 2015, 33 (3), 286 - 327.

16. Shamaila, S., Zafar, N., Riaz, S., Sharif, R., Nazir, J., Naseem, S. Nanomaterials, 2016, 6, 71; doi:10.3390/nano6040071.

17. Fei, L., Perret, S. Int. J.Mol. Sci. 2009. 10, 646-655.

18. Piruthiviraj, P., Margret, A., Krishnamurthy, P. P. Appl Nanosci, 2015, 1-7. 